\title{
Determination of Settlement for Beam on Elastic Foundation by ETABS Software
}

\author{
Ibrahim S. I. Harba \\ Civil Engineering Department \\ Al- Nahrain University, Baghdad, Iraq \\ ibraharba@yahoo.com \\ Received: 3-April-2017 \\ Revised: 19-June-2017 \\ Oday S. B. AL Rubaie \\ Civil Engineering Department \\ Al- Nahrain University, Baghdad, Iraq \\ oday_sahib@yahoo.com \\ https://doi.org/10.29194/NJES21010012
}

\begin{abstract}
In this study a numerical examples and solutions has been obtained by using three system of beam resting on elastic foundation (BOEF) which was adopted previously by three different engineering software. The first part of this paper was related to verify the model of (BOEF) by using ETABS2015 by make a comparison with previous results by determination the maximum settlements at the mid of span which show a good agreement between ETABS2015 and other results, where the total differences was vary from $2.13 \%$ to $3.27 \%$. . The second part of this study was highlighted on the settlement of BOEF with different parametric study (beam thickness, soil subgrade reaction $\left(K_{S}\right)$ and the load location), case (1) was selected for this goal. In this paper it is found that the differential settlement along the beam are decrease as increasing in the beam stiffness in addition to possibility to obtain uplift (positive settlement ) for some type of changing in the load location specially for higher thick beam. It was noticed that the settlement are increased significantly as reducing in the $\left(\mathrm{K}_{\mathrm{S}}\right)$. Finally this study show a different form of deflection by combination two of parametric study.
\end{abstract}

Keyword: Soil subgrade reaction, beam , elastic foundation, settlement, ETABS

\section{1-Introduction}

one of the simplest methods to representing strip or companied footings for analyzing the forces and settlement under these footings is by considering a beam resting on elastic foundation which it is well known as Beam on Elastic Foundation (BOEF). Where the reaction forces of the soil under the beam are proportional to the settlement of the beam at each point along the footing. That is to say foundation resting on individual spring has own identical ,independent , linearly and closely spaced for each to other with knowing value of spring stiffness to produce a modulus of subgrade reaction which also known as the soil stiffness or soil reaction in force divided by cubic distance (kips/in ${ }^{3}, \mathrm{kN} / \mathrm{m}^{3}$, ..etc. ) $\mathrm{K}_{\mathrm{s}}$ in the vertical direction $(\mathrm{z})$. Which it is considered as the intensity of the reaction force on foundation pressure. The bed of springs is used to determine the deformation, shear and moments in different type of foundations which become the bases of structural design. Also the springs use to represent the interaction between the soil and the foundation which producing by Winkler [1] and developed later by Heteyni [2] and Kerr [3] ,thus this model some time called a Winkler foundation , Beam on elastic foundation analysis or Winkler method

Where the $K_{S}$ is the soil subgrade reaction and can be obtained by using the plate-load test data

$$
\mathrm{K}_{\mathrm{s}}=\mathrm{q} / \delta
$$

$\mathrm{q}$ is the load in force per area , $\delta$ is the settlement Vesic'[4] suggested another formula to find out the value of the $K_{S}$ by using the stress-strain modulus as shown in the equation.

$$
\mathrm{K}_{\mathrm{S}}{ }^{\prime}=0.65\left(\mathrm{E}_{\mathrm{S}} \mathrm{B}^{4} / \mathrm{E}_{\mathrm{F}} \mathrm{I}_{\mathrm{F}}\right)^{1 / 12} \mathrm{x}\left(\mathrm{E}_{\mathrm{S}} / 1-\mathrm{u}^{2}\right)
$$

$\mathrm{B}, \mathrm{I}_{\mathrm{F}}$ and $\mathrm{E}_{\mathrm{F}}$ are the foundation properties, width, moment of inertial and modulus of elasticity respectively. Bowles [5] stated that 'Since the twelfth root of any value multiplied by 0.65 will be close to 1 , for all practical purposes the Vesic's equation reduces to'

$$
\mathrm{K}_{\mathrm{S}}^{\prime}=\left(\mathrm{E}_{\mathrm{S}} / 1-\mathrm{u}^{2}\right)
$$

Where the $E_{S}$ and $u$ are the modulus of elasticity and Poisson's ratio for soil respectively. Finally the soil subgrade reaction $K_{S}$ can be expressed as following equation .

$$
\mathrm{K}_{\mathrm{S}}=\mathrm{K}_{\mathrm{S}} / \mathrm{B}
$$

Where much software is formulated to analysis such as these problems like the aforementioned engineering program which used in this study to make the comparison by considering the absolute percentage.

$$
\mathrm{R} \%=\frac{\mathrm{W} 1-\mathrm{W} 0}{\mathrm{~W} 0} \mathrm{x} \%
$$

$\mathrm{R} \%$ is the percentage of absolute of deference of two values

$\mathrm{W}_{0}$ is the value of displacement of the independent

$\mathrm{W}_{1}$ is the value of displacement of the ETABS model

\section{2-ETABS modeling}

In previous studies many engineering software has been used, Ronald JANCO [6] used the ANSSYS to model and analysis a beam on elastic 
foundation . Yun-gang Zhan [7] use the ABAQUS in modeling beam on elastic foundation using plate element in finite method. Determination of settlement in this study was done by using commercial software ETABS2015 [8] which is a finite element tool to use for analyzes the beams subjected to concentrated load. Representing the elastic continuum is difficult method due to the complexity nature of soil; Winkler model is the principle of the analysis of foundation used in the soft was by substituting of soil subgrade reaction $\left(\mathrm{K}_{\mathrm{s}}\right)$ to compute the settlement under the beam on elastic foundation.

\section{3-Numerical examples for beams on elastic foundation \\ 3-1 Verification \\ 3-1-1 Case (1):}

An example for beam on elastic foundation obtained from LARSA4D [9] which used the example of Heteyni [2] (independent value of settlement). Both of these results will be used to compare with those results which obtained by using the ETABS 2015 where the aforementioned example has the following data:-

1-Beam of thickness (1 inch) with (3 inches) wide and (30 inches) long. Modules of elasticity of material $\mathrm{E}=30,000 \mathrm{Ksi}$

2-Cross section will yield moment of inertia equal to $\left(0.25 \mathrm{in}^{4}\right)$ and area of $\left(3 \mathrm{in}^{2}\right)$

3 - The soil subgrade reaction is equal to (5000 $\mathrm{lb} / \mathrm{in}^{3}$ )

4- Beam subjected to concentrated load in the middle of span with ( $\mathrm{P}=8 \mathrm{kip})$ as shown in the Figure (1) .

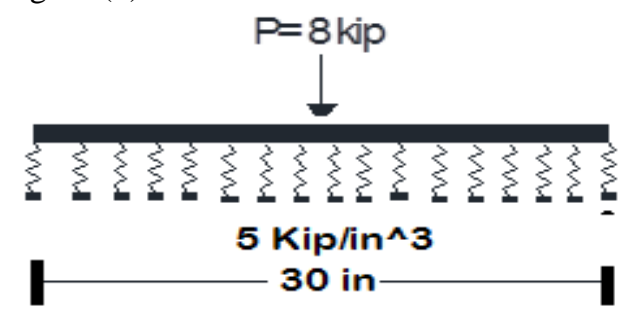

Figure (1): Beam on elastic foundation ,after [9]

Beam showing in the Figure (1) can be modeling for ETABS as shown in the Figure (2)

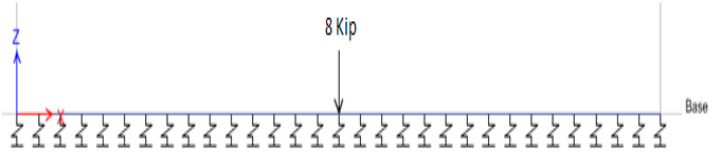

Figure (2): Modeling shape for beam of case (1)

\section{3-1-2 Case (2):}

An example for beam on elastic foundation obtained from ELPLA [10] which used the example of Rombach [11] (independent value of settlement ) these result of both aforementioned reference will be used to compared with those result which obtained by using the commercial software of ETABS 2015 where the aforementioned example has the following data:1 - Strip footing of thickness $(\mathrm{d}=0.6 \mathrm{~m})$ and length ( $\mathrm{L}=5 \mathrm{~m})$ to be consider

2- The analysis was carried out for (1 m ) width

3 - The cross section of the beam yield a moment of inertia $\mathrm{I}_{\mathrm{yy}}$ equal to $\left(0.018 \mathrm{~m}^{4}\right)$

4- The soil subgrade reaction is equal to $(50,000$ $\mathrm{kN} / \mathrm{m}^{3}$ )

5 -The beam subjected to wall load of $(\mathrm{P}=1000$ $\mathrm{kN} / \mathrm{m}$ ) at the center, Figure (3)

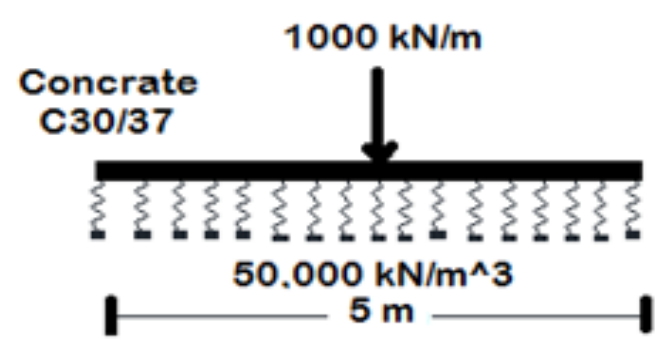

Figure (3): Beam on elastic foundation, after [10]

Beam showed in Fig. (3) can be modeling for ETABS as shown in the Fig.(4)

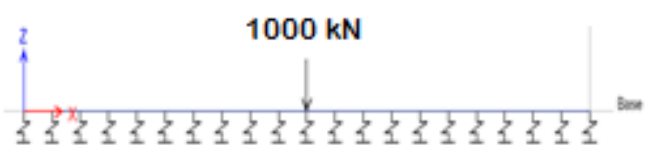

Figure (4): Modeling shape for beam of case (2) 3-1-3 Case (3):

An example for beam on elastic foundation obtained from software verification for SAP 2000 [12] which used the example of Timoshenko [13] (independent value of settlement) both of these result will be used to compared with those result which obtained by using the commercial software of ETABS 2015 where the aforementioned example has the following data:-

1-Simply supported beam of width of (b =36 in) and depth of ( $d=36 \mathrm{in})$ and length $(\mathrm{L}=15 \mathrm{ft})$ to be consider

2-The cross section of the beam yield a moment of inertia $\mathrm{I}_{\mathrm{yy}}$ equal to $\left(139968 \mathrm{in}^{4}\right)$

3-The modulus of elasticity of beam is equal to (4000 ksi)

4-Soil subgrade reaction equal to $\left(800 \mathrm{kip} / \mathrm{ft}^{3}\right)$

5- Beam subjected to concentrated load in the middle of span with $\mathrm{P}=500$ kip as shown in the figure below:- 


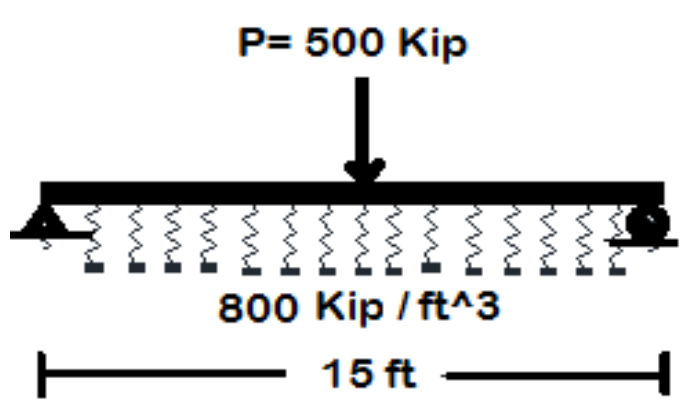

Figure (5): Simply supported beam on elastic foundation, after [12]

Beam showing in the Figure (5) can be modeling for ETABS as shown in the Figure(6)

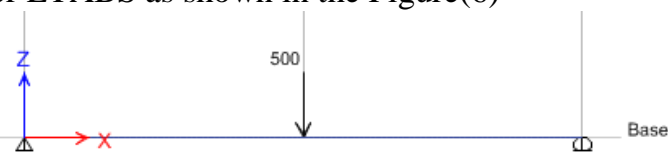

Figure (6): Modeling shape for beam of case (3)

\section{3-2 Results and discussions}

After modeling of the previous three cases by using ETABS2015 with same properties and boundary conditions a deform shape can be obtain for each example as showing in the following Figures .

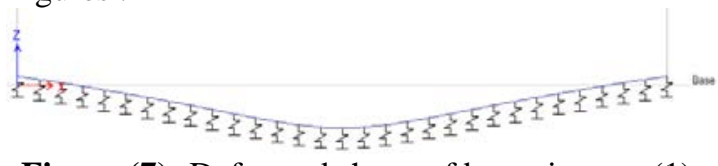

Figure (7): Deformed shape of beam in case (1)

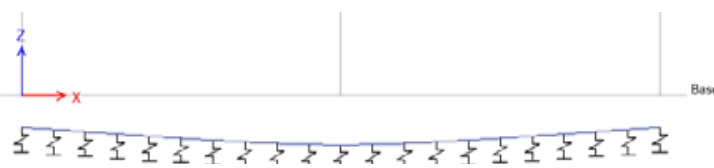

Figure (8): Deformed shape of beam in case (2)

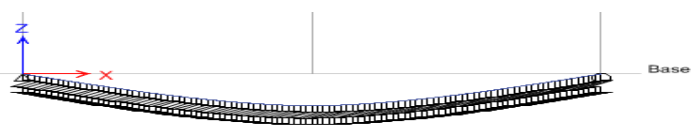

Figure (9): Deformed shape of beam in case (3)

A results of settlement in the middle of span according to the independent reference of Heteyni[2] , Rombach[11] and Timoshenko[13] in addition to engineering program of LARSA4D[9] , ELPLA[10], SAP2000[12] and ETABS for the cases of 1,2 and 3 respectively are tabulated in the Tables of 1,2 and 3 which showing the absolute difference ratio of $2.27 \%, 2.13 \%$ and $3.27 \%$ respectively

Table (1): Settlement value for case (1) in the mid of span

\begin{tabular}{|l|c|c|c|c|}
\hline \multirow{2}{*}{ Point } & \multicolumn{4}{|c|}{ Displacement (in) } \\
\cline { 2 - 5 } & Heteyni & LARSA4D & ETABS & R\% \\
\hline
\end{tabular}

\begin{tabular}{|l|l|l|l|l|}
\hline $\begin{array}{l}\text { Mid. } \\
\text { span }\end{array}$ & 0.04348 & 0.043478 & 0.042493 & 2.27 \\
\hline
\end{tabular}

Table (2): Settlement value for case (2) in the mid of span

\begin{tabular}{|c|c|c|c|c|}
\hline \multirow{2}{*}{ Point } & \multicolumn{4}{|c|}{ Displacement (in) } \\
\cline { 2 - 5 } & $\begin{array}{c}\text { Rombach } \\
2000\end{array}$ & ELPLA & ETABS & R\% \\
\hline $\begin{array}{c}\text { Middle } \\
\text { of span }\end{array}$ & 0.47 & 0.46 & 0.48 & 2.13 \\
\hline
\end{tabular}

Table (3): Settlement value for case (3) in the mid of span

\begin{tabular}{|c|c|c|c|c|}
\hline \multirow{2}{*}{ Point } & \multicolumn{4}{|c|}{ Displacement (in) } \\
\cline { 2 - 5 } & Timoshenko & SAP2000 & ETABS & R\% \\
\hline $\begin{array}{c}\text { Middle } \\
\text { of span }\end{array}$ & 0.08933 & 0.08933 & 0.08614 & 3.27 \\
\hline
\end{tabular}

It can be noted that there is a minor differences in the results between the ETABS 2015 results and the independent values (Heteyni, Rombach 2000 and Timoshenko) it is may be come due to some differences in the input data but still consider as acceptable tolerance (less than 5\%).

\section{4- Parametric study}

After verifying the modeling of beam on elastic foundation by using ETABS 2015 [8] where all result is agree well with other software. In this part of this study a three aspects of beam thickness, soil subgrade reaction $\left(k_{s}\right)$ and load location to figure out the effect of each aforementioned aspect on the settlement of beam by adopting example (1) .

In this section the study will discuss the impact of some parametric study on the settlement of beam on elastic foundation where the parametric study is consist of the following items:-

\section{a- Effect of beam thickness}

A thickness of $0.5,1,2,3,4$ and 5 inches for the beam of case (1) are adopted to investigate the settlement under concentrated load with the same specification where the value of aforementioned thickness was only changing in each program of ETABS2015 running.

b- Effect of the location of concentrated load It is will be done by changing the location of load of 8 kips from node $(x=0)$ to the midpoint of beam as mentioned before where the distance of $(x=15)$ inches at each interval of 3 inches as appear in Figure (10) below

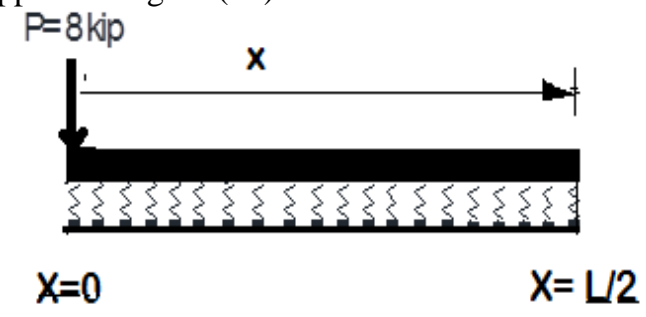


Figure (10): Individualized beam of 30 inches

To figure out the how can the location of load effect on the settlement of beam on elastic foundation

\section{c- Effect subgrade reaction $\left(\mathbf{K}_{\mathrm{s}}\right)$}

To determine the impact of soil subgrade reaction on the settlement of beam on elastic foundation subjected to concentrated load with the same specification of materials and other circumstances of case (1), a different value of subgrade reaction of $3 \times 10^{3}, 4 \times 10^{3}, 5 \times 10^{3}, 6 \times 10^{3}$ and $7 \times 10^{3} \mathrm{lb} / \mathrm{in}^{3}$ will be used to find out the effect of soil subgrade reaction on the settlement of beam resting on elastic foundation.

In addition to combination of effect of beam thickness with the rest of parametric study separately

\section{4-1 Results and discussion}

\section{4-1-1 Effect of beam thickness}

By increasing the beam thickness from 0.5 to 5 inches as mentioned previously it can observe that there is a reducing in both of settlement at the mid of span and the differential settlement along the beam where the load at mid span as shown in the Table no. 1 in appendix A .For more clearance all results in the aforementioned appendix will be used create a chart showing the changing in the value of settlement due to increasing in the beam thickness. It is also can be notice that the deflected shape of beam transform from curvature to be Simi line as increasing in beam thickness as shown in Figure (11) below :-

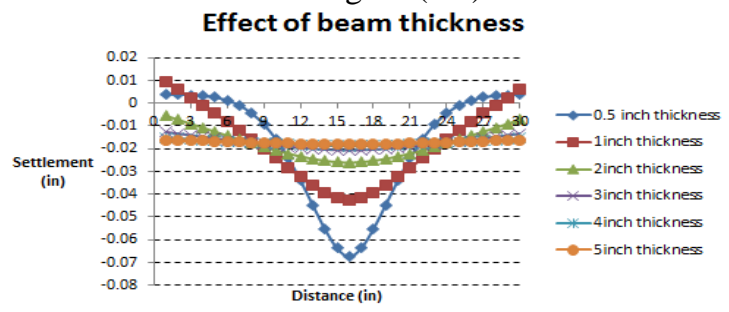

Figure (11): Effect of beam thickness

\section{4-1-2 Effect of location of concentrated load}

As the load are moving from the edge to the midpoint of beam (0.6 inch thick) a different values of settlement at each node can be seen as shown in Table no.2 in appendix A . All result mentioned in table no.2 are used to create a chart showing the changing in the value of settlement in nodes for each for each changing in the load location along the beam as shown in the Figure (12)

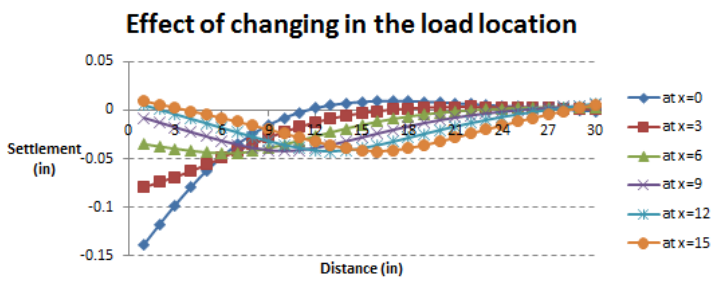

Figure (12): Effect of the load location

The Figure above exhibit two kind of deflection (positive and negative ) which they are keeping in changing according to load location . Both effects of the load location and beam thickness are toke in the consideration by using ETABS for modeling abeam with different load location and different value of thickness which can be summarized in the following Figures :

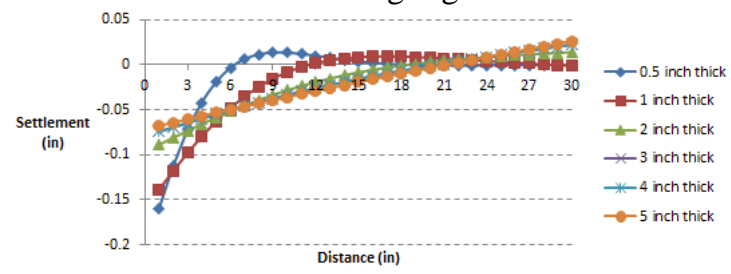

Figure (13): Different values of thickness for load at $\mathrm{x}=0$

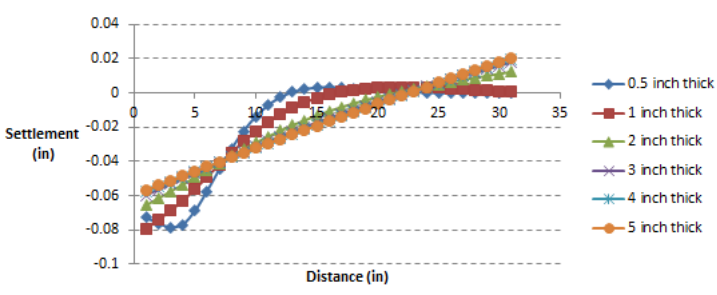

Figure (14): Different values of thickness for

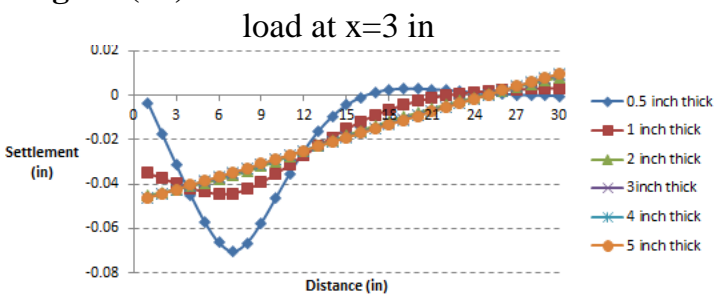

Figure (15): Different values of thickness for

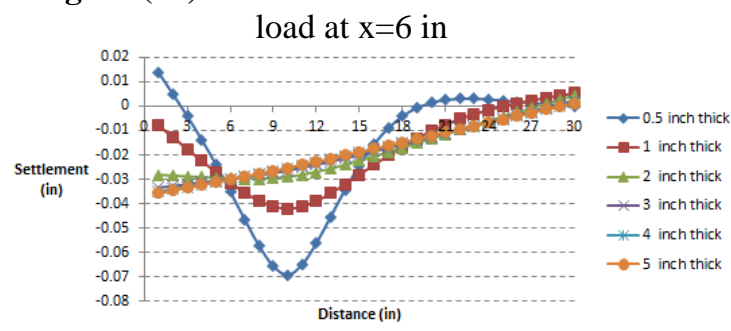

Figure (16): Different values of thickness for load at $\mathrm{x}=9$ in

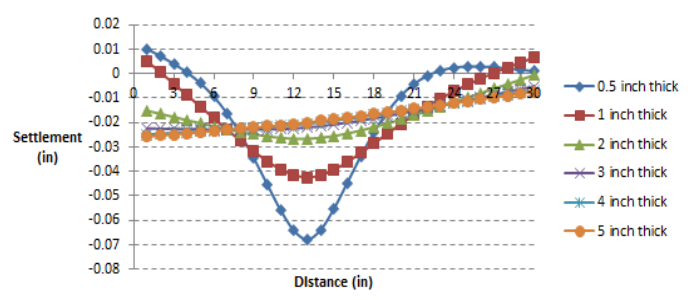

Figure (17): Different values of thickness for load at $\mathrm{x}=12$ in

And finally for different values of thickness for load allocated at the center of the span which is 
similar to Figure (11) as shown below in Figure (18)

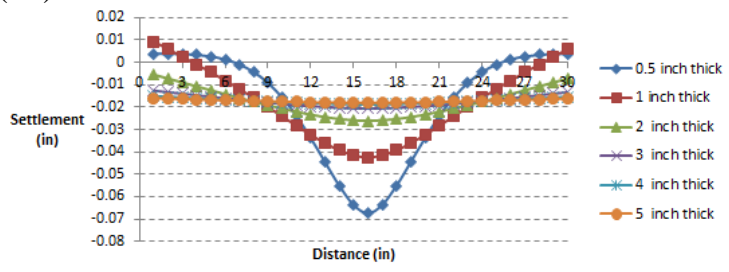

Figure (18): Different values of thickness for load at $\mathrm{x}=15$ in

From above Figures it can be noted that increasing the beam thickness are working to reduce both of the settlement and the differential settlement and as mentioned above. While the changing in the load location are working to change the shape of deflection and the location of both positive and negative settlement

4-1-3 Effect of soil subgrade reaction $\left(K_{s}\right)$

Settlement at each node along the beam of case (1) by using a different values of soil subgrade reaction are tabulated in Appendix A Table (3) where the values of settlement along the beam are used to create a chart as shown in the figure (19) which exhibit obvious increasing in the settlement at the midpoint of beam as the soil subgrade reaction are decrease .

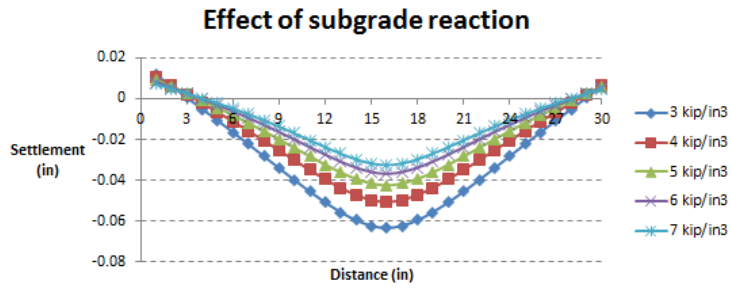

Figure (19): Effect of the soil subgrade reaction

Similarly to the previous part of this study a lot of charts are obtain by combination the effect of subgrade reaction and different values of thickness as showing below:

By reviewing the charts it is clearly to notice that all figures give the same shape of deflection but in different values of settlement depending on values of both soil subgrade reaction and the beam thickness for the same location of concentrated load (at the midpoint of beam )

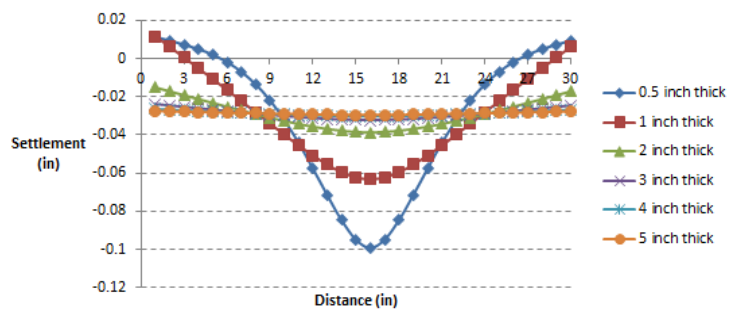

Figure (20): Effect of different value of thickness for beam resting on soil subgrade reaction of $3 \mathrm{ksi} / \mathrm{in}$

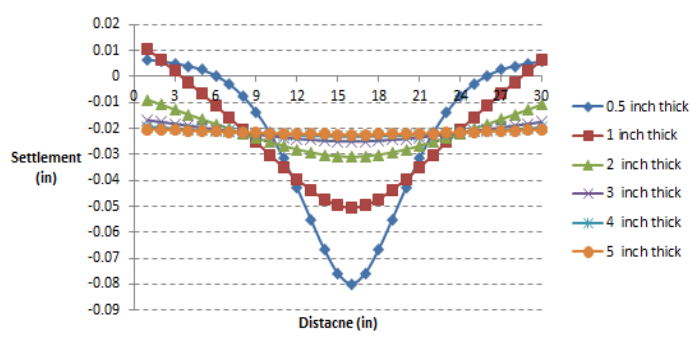

Figure (21): Effect of different value of thickness for beam resting on soil subgrade reaction of $4 \mathrm{ksi} / \mathrm{in}$

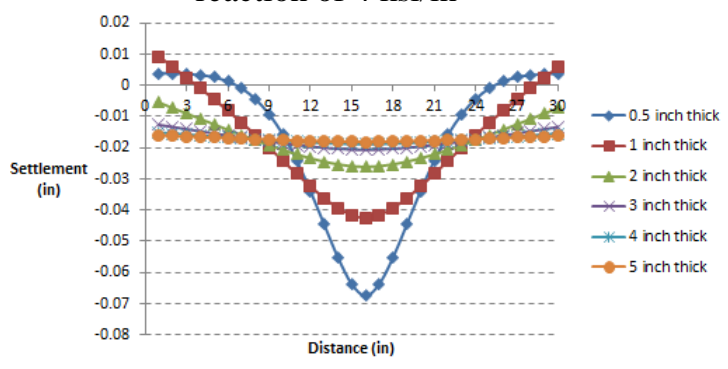

Figure (22): Effect of different value of thickness for beam resting on soil subgrade reaction of 5 ksi/in

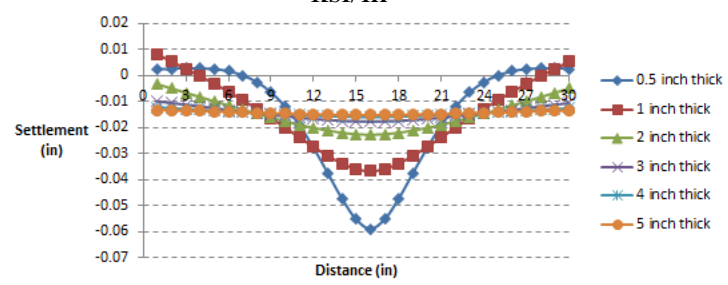

Figure (23): Effect of different value of thickness for beam resting on soil subgrade reaction of 6 ksi/in

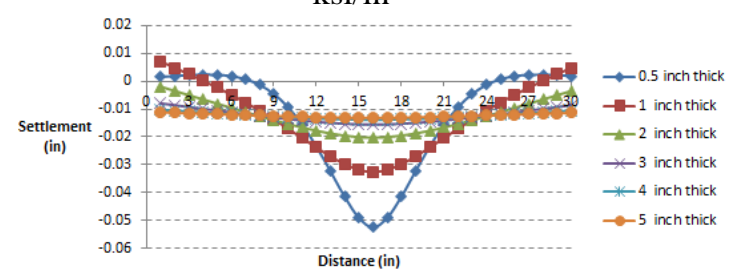

Figure (24): Effect of different value of thickness for beam resting on soil subgrade reaction of 7 $\mathrm{ksi} / \mathrm{in}$

\section{5-Conclusion}

In spite of the commercial software of ETABS2015 are specialized for analysis and design of the super-structure frame but through the study we show that the modeling of Beam On Elastic Foundation (BOEF) could be implemented by ETABS2015 with accurate results by obtaining a good agreement with the other engineering software. In connection with parametric study we can notice the following conclusions

a- Regarding the effect of beam thickness, it can be noted that both of the settlement and differential settlement was reduce as the beam thickness is increase where the deflected shape will become semi-line and the reduction in the settlement and the differential settlement along 
the beam are from $37.04 \%$ to $73.17 \%$ and from $78.09 \%$ to $11.24 \%$ respectively .

b- The change in load location gives a different shape of settlement in addition to different sign of settlement (positive and negative )

c- By using a different values of subgrade reaction which can be consider as indicator of the soil stiffness, the value of settlement was decrease as the soil subgrade reaction was increase, with approximately of keeping on the shape of settlement as curve due to location of load in the mid of foundation span.

\section{References}

1- Winkler, E. (1867) Die Lehre Von Der Elastizitat Und Festigkeit. Dominicus, Prague.

2- M. Heteyni, "Beams on Elastic Foundation", University of Michigan Press, Ann Arbor, Michigan, 1967.

3- Kerr, A. D. (1964) "Elastic and Viscoelastic Foundation Models. Journal. Applied Mechanics 31: 491-498.

4- Vesic, A. B., (1961) "Beams on Elastic Solid Subgrade and the Hypothesis", Proceedings $5^{\text {th }}$ International Conference on Soil Mechanics and Foundation Engineering, Vol. 1, pp. 845-850.
5- Bowles, J. E., (1996), "Foundation Analysis and Design", $5^{\text {th }}$ edition, McGraw-Hill Companies, Inc, Singapore

6- Ronald JANCO ,(2010), “Solution Method For Beam and Frames on Elastic Foundation Using the Finite Element Method” , International Scientific Conference MSFE 2010

7- Yun-gang Zhan, (2012) ,’Modeling Beam On Elastic Foundation Using Plate in Finite Element Method, Electronic Journal of Geotechnical Engineering, Volume 17 [2012]

8- ETABS 2015 ,Computer and Structure, INC. Structural and Earthquake Engineering software 9- LARSA 4D Finite Element Analysis And Design Software Last Revised October 2016 10-GEOTEC Software Inc.” Examples to verify and Illustrate ELPLA “ PO Box 14001 Richmond Road PO Calgary AB, Canada T3E 7Y7

11-Rombach, G.(2000): Anwendung der FinitElement-Method im Betonbau Ernst\&Sohn, Berlin.

12-Sap2000 software verification revision no. 0.1 , example 1-013 "simply supported beam on elastic foundation

13-Timoshenko, S. P. and Goodier, J. N., (1970)

"Theory of Elasticity", McGraw-Hill, New York, $3^{\text {rd }}$ Edition

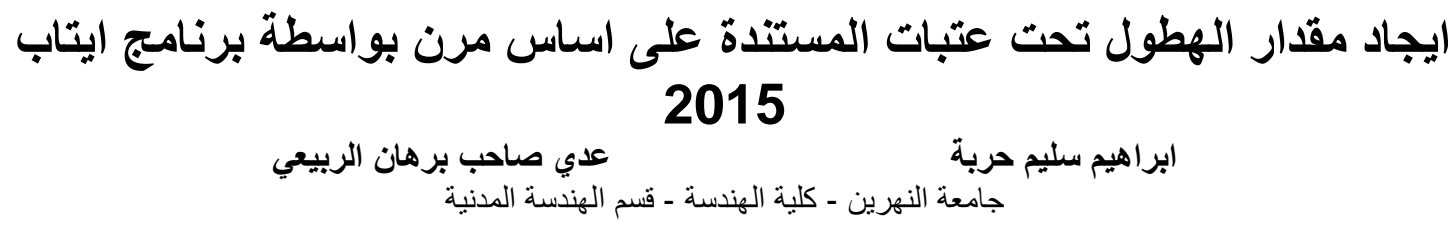

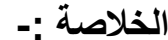

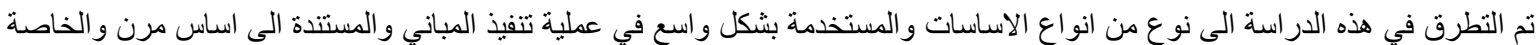

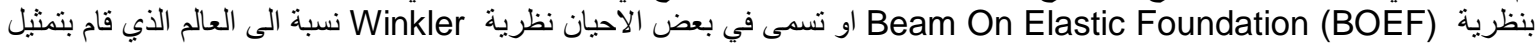

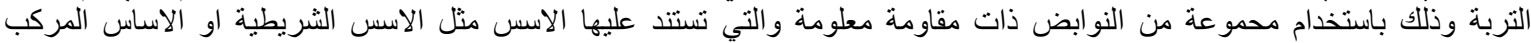
companied and strip footings الحاملة للاوزان حيث تم استخدام البرنامج الهندسي

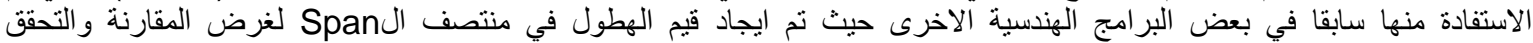

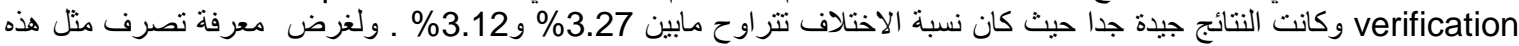

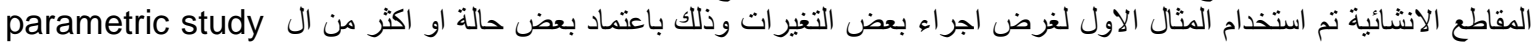

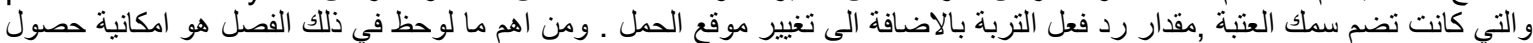

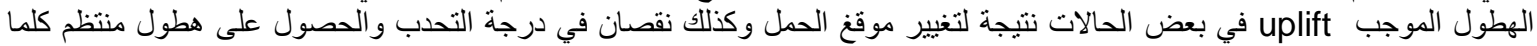

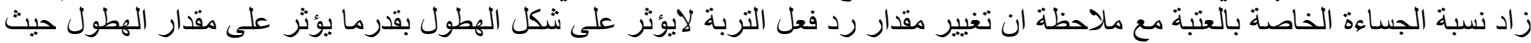
Appendix (A)

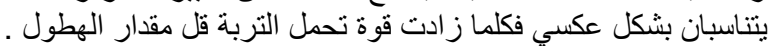

\begin{tabular}{|c|c|c|c|c|c|c|}
\hline $\begin{array}{c}\text { Team } \\
\text { thickness } \\
\text { (in ) }\end{array}$ & 0.5 & 1 & 2 & 3 & 4 & 5 \\
\hline Node no. & \multicolumn{7}{|c|}{ Table (A- 1) } \\
\hline 1 & 0.003932 & 0.009309 & -0.005482 & -0.01264 & -0.015094 & -0.01607 \\
\hline 2 & 0.003849 & 0.005923 & -0.007235 & -0.013327 & -0.015409 & -0.016236 \\
\hline 3 & 0.003696 & 0.00252 & -0.008989 & -0.014015 & -0.015725 & -0.016404 \\
\hline 4 & 0.003349 & -0.000932 & -0.01074 & -0.014702 & -0.016041 & -0.016573 \\
\hline 5 & 0.002626 & -0.004469 & -0.012483 & -0.015385 & -0.016356 & -0.016741 \\
\hline 6 & 0.00129 & -0.008125 & -0.01421 & -0.016061 & -0.016668 & -0.016909 \\
\hline
\end{tabular}




\begin{tabular}{|c|c|c|c|c|c|c|}
\hline 7 & -0.000935 & -0.011925 & -0.015911 & -0.016725 & -0.016975 & -0.017074 \\
\hline 8 & -0.004347 & -0.015877 & -0.017571 & -0.017369 & -0.017274 & -0.017235 \\
\hline 9 & -0.009223 & -0.019969 & -0.019172 & -0.017987 & -0.01756 & -0.01739 \\
\hline 10 & -0.015771 & -0.024152 & -0.02069 & -0.018569 & -0.017831 & -0.017538 \\
\hline 11 & -0.024048 & -0.02834 & -0.022099 & -0.019106 & -0.018082 & -0.017675 \\
\hline 12 & -0.033855 & -0.032399 & -0.023364 & -0.019586 & -0.018307 & -0.0178 \\
\hline 13 & -0.044605 & -0.036137 & -0.024449 & -0.019997 & -0.018501 & -0.017908 \\
\hline 14 & -0.05517 & -0.039297 & -0.025308 & -0.020322 & -0.018658 & -0.017998 \\
\hline 15 & -0.063707 & -0.041552 & -0.025892 & -0.020548 & -0.01877 & -0.018064 \\
\hline 16 & -0.067494 & -0.042493 & -0.026143 & -0.020655 & -0.01883 & -0.018105 \\
\hline 17 & -0.063707 & -0.041552 & -0.025892 & -0.020548 & -0.01877 & -0.018064 \\
\hline 18 & -0.05517 & -0.039297 & -0.025308 & -0.020322 & -0.018658 & -0.017998 \\
\hline 19 & -0.044605 & -0.036137 & -0.024449 & -0.019997 & -0.018501 & -0.017908 \\
\hline 20 & -0.033855 & -0.032399 & -0.023364 & -0.019586 & -0.018307 & -0.0178 \\
\hline 21 & -0.024048 & -0.02834 & -0.022099 & -0.019106 & -0.018082 & -0.017675 \\
\hline 22 & -0.015771 & -0.024152 & -0.02069 & -0.018569 & -0.017831 & -0.017538 \\
\hline 23 & -0.009223 & -0.019969 & -0.019172 & -0.017987 & -0.01756 & -0.01739 \\
\hline 24 & -0.004347 & -0.015877 & -0.017571 & -0.017369 & -0.017274 & -0.017235 \\
\hline 25 & -0.000935 & -0.011925 & -0.015911 & -0.016725 & -0.016975 & -0.017074 \\
\hline 26 & 0.00129 & -0.008125 & -0.01421 & -0.016061 & -0.016668 & -0.016909 \\
\hline 27 & 0.002626 & -0.004469 & -0.012483 & -0.015385 & -0.016356 & -0.016741 \\
\hline 28 & 0.003349 & -0.000932 & -0.01074 & -0.014702 & -0.016041 & -0.016573 \\
\hline 29 & 0.003696 & 0.00252 & -0.008989 & -0.014015 & -0.015725 & -0.016404 \\
\hline 30 & 0.003849 & 0.005923 & -0.007235 & -0.013327 & -0.015409 & -0.016236 \\
\hline 31 & 0.003932 & 0.009309 & -0.005482 & -0.01264 & -0.015094 & -0.01607 \\
\hline
\end{tabular}

Table (A- 2)

\begin{tabular}{|c|c|c|c|c|c|c|}
\hline $\begin{array}{c}\text { The location } \\
\text { of load }\end{array}$ & $\mathrm{x}=0$ & $\mathrm{x}=3$ & $\mathrm{x}=6$ & $\mathrm{x}=9$ & $\mathrm{x}=12$ & $\mathrm{x}=15$ \\
\hline Node no. & \multicolumn{5}{|c|}{} \\
\hline 1 & -0.13825 & -0.07941 & -0.03506 & -0.00796 & 0.005188 & 0.009309 \\
\hline 2 & -0.11764 & -0.0742 & -0.03743 & -0.01282 & 0.000546 & 0.005923 \\
\hline 3 & -0.09785 & -0.06885 & -0.03973 & -0.01766 & -0.00411 & 0.00252 \\
\hline 4 & -0.07941 & -0.06304 & -0.04183 & -0.02245 & -0.00878 & -0.00093 \\
\hline 5 & -0.06269 & -0.05625 & -0.04349 & -0.02711 & -0.01348 & -0.00447 \\
\hline 6 & -0.04788 & -0.04905 & -0.04441 & -0.03152 & -0.0182 & -0.00813 \\
\hline 7 & -0.03506 & -0.04183 & -0.0442 & -0.03549 & -0.02289 & -0.01193 \\
\hline 8 & -0.0242 & -0.03487 & -0.04229 & -0.0388 & -0.02747 & -0.01588 \\
\hline 9 & -0.01522 & -0.02836 & -0.03925 & -0.04114 & -0.03182 & -0.01997 \\
\hline 10 & -0.00796 & -0.02245 & -0.03549 & -0.04211 & -0.03577 & -0.02415 \\
\hline 11 & -0.00227 & -0.0172 & -0.03135 & -0.04118 & -0.03907 & -0.02834 \\
\hline 12 & 0.002052 & -0.01265 & -0.02708 & -0.03892 & -0.04142 & -0.0324 \\
\hline 13 & 0.005188 & -0.00878 & -0.02289 & -0.03577 & -0.04241 & -0.03614 \\
\hline 14 & 0.007329 & -0.00558 & -0.0189 & -0.03208 & -0.04149 & -0.0393 \\
\hline 15 & 0.008648 & -0.00298 & -0.01523 & -0.02814 & -0.03926 & -0.04155 \\
\hline 16 & 0.009309 & -0.00093 & -0.01193 & -0.02415 & -0.03614 & -0.04249 \\
\hline 17 & 0.009454 & 0.000626 & -0.00902 & -0.02028 & -0.03246 & -0.04155 \\
\hline 18 & 0.009208 & 0.001763 & -0.00652 & -0.01664 & -0.02851 & -0.0393 \\
\hline 19 & 0.008678 & 0.002544 & -0.00441 & -0.0133 & -0.02449 & -0.03614 \\
\hline 20 & 0.007952 & 0.003031 & -0.00267 & -0.0103 & -0.02056 & -0.0324 \\
\hline 21 & 0.007099 & 0.00328 & -0.00125 & -0.00764 & -0.01681 & -0.02834 \\
\hline 22 & 0.006175 & 0.003341 & -0.00013 & -0.00533 & -0.0133 & -0.02415 \\
\hline 23 & 0.005219 & 0.003259 & 0.000746 & -0.00333 & -0.01007 & -0.01997 \\
\hline 24 & 0.004259 & 0.003069 & 0.001415 & -0.00161 & -0.00711 & -0.01588 \\
\hline 25 & 0.003312 & 0.002804 & 0.001919 & -0.00013 & -0.00441 & -0.01193 \\
\hline 26 & 0.002388 & 0.002486 & 0.002296 & 0.001161 & -0.00193 & -0.00813 \\
\hline 27 & 0.001489 & 0.002135 & 0.002581 & 0.002304 & 0.000374 & -0.00447 \\
\hline 28 & 0.000612 & 0.001764 & 0.002804 & 0.003341 & 0.002544 & -0.00093 \\
\hline & & & & & & \\
\hline
\end{tabular}




\begin{tabular}{|c|c|c|c|c|c|c|}
\hline 29 & -0.00025 & 0.001383 & 0.002988 & 0.004313 & 0.004626 & 0.00252 \\
\hline 30 & -0.0011 & 0.000998 & 0.003153 & 0.00525 & 0.00666 & 0.005923 \\
\hline 31 & -0.00195 & 0.000612 & 0.003312 & 0.006175 & 0.008678 & 0.009309 \\
\hline
\end{tabular}

Table (A- 3)

\begin{tabular}{|c|c|c|c|c|c|}
\hline $\begin{array}{c}\text { Subgrade } \\
\text { reaction value }\end{array}$ & $3 \mathrm{kip} / \mathrm{in}^{3}$ & $4 \mathrm{kip} / \mathrm{in}^{3}$ & $5 \mathrm{kip} / \mathrm{in}^{3}$ & $6 \mathrm{kip} / \mathrm{in}^{3}$ & $7 \mathrm{kip} / \mathrm{in}^{3}$ \\
\hline Node no. & \multicolumn{5}{|l|}{} \\
\hline 1 & 0.011643 & 0.010603 & 0.009309 & 0.008126 & 0.007113 \\
\hline 2 & 0.006082 & 0.00634 & 0.005923 & 0.005369 & 0.004826 \\
\hline 3 & 0.000508 & 0.002061 & 0.00252 & 0.002594 & 0.002521 \\
\hline 4 & -0.005102 & -0.002262 & -0.000932 & -0.000232 & 0.000164 \\
\hline 5 & -0.010769 & -0.00666 & -0.004469 & -0.00315 & -0.002288 \\
\hline 6 & -0.01651 & -0.01116 & -0.008125 & -0.006196 & -0.004875 \\
\hline 7 & -0.022328 & -0.015778 & -0.011925 & -0.009402 & -0.007632 \\
\hline 8 & -0.028207 & -0.020514 & -0.015877 & -0.012785 & -0.010581 \\
\hline 9 & -0.034104 & -0.025341 & -0.019969 & -0.016338 & -0.013722 \\
\hline 10 & -0.03994 & -0.030201 & -0.024152 & -0.020023 & -0.017026 \\
\hline 11 & -0.045599 & -0.034992 & -0.02834 & -0.023766 & -0.020424 \\
\hline 12 & -0.050915 & -0.039567 & -0.032399 & -0.027441 & -0.023801 \\
\hline 13 & -0.055666 & -0.043722 & -0.036137 & -0.030867 & -0.026984 \\
\hline 14 & -0.05957 & -0.04719 & -0.039297 & -0.033798 & -0.029735 \\
\hline 15 & -0.06228 & -0.049633 & -0.041552 & -0.035911 & -0.031737 \\
\hline 16 & -0.063374 & -0.050637 & -0.042493 & -0.036805 & -0.032593 \\
\hline 17 & -0.06228 & -0.049633 & -0.041552 & -0.035911 & -0.031737 \\
\hline 18 & -0.05957 & -0.04719 & -0.039297 & -0.033798 & -0.029735 \\
\hline 19 & -0.055666 & -0.043722 & -0.036137 & -0.030867 & -0.026984 \\
\hline 20 & -0.050915 & -0.039567 & -0.032399 & -0.027441 & -0.023801 \\
\hline 21 & -0.045599 & -0.034992 & -0.02834 & -0.023766 & -0.020424 \\
\hline 22 & -0.03994 & -0.030201 & -0.024152 & -0.020023 & -0.017026 \\
\hline 23 & -0.034104 & -0.025341 & -0.019969 & -0.016338 & -0.013722 \\
\hline 24 & -0.028207 & -0.020514 & -0.015877 & -0.012785 & -0.010581 \\
\hline 25 & -0.022328 & -0.015778 & -0.011925 & -0.009402 & -0.007632 \\
\hline 26 & -0.01651 & -0.01116 & -0.008125 & -0.006196 & -0.004875 \\
\hline 27 & -0.010769 & -0.00666 & -0.004469 & -0.00315 & -0.002288 \\
\hline 28 & -0.005102 & -0.002262 & -0.000932 & -0.000232 & 0.000164 \\
\hline 29 & 0.000508 & 0.002061 & 0.00252 & 0.002594 & 0.002521 \\
\hline 30 & 0.006082 & 0.00634 & 0.005923 & 0.005369 & 0.004826 \\
\hline 31 & 0.011643 & 0.010603 & 0.009309 & 0.008126 & 0.007113 \\
\hline & & & & & \\
\hline & & & & \\
\hline & & & &
\end{tabular}

